\title{
ANÁLISE ECONÔMICO-FINANCEIRA DE UM NOVO PROCESSO DE PRODUÇÃO DE DERIVADOS DE MILHO
}

\author{
Claudinéia Aparecida Queli Geraldi ${ }^{1}$ \\ Nehemias Curvelo Pereiral \\ Laercio Montovani Frare ${ }^{2}$ \\ Túlio Klassen ${ }^{3}$
}

\begin{abstract}
Resumo: $\mathrm{O}$ objetivo deste trabalho foi desenvolver um novo processo para a produção de amido de milho e seus subprodutos em substituição ao processo tradicional. O novo processo levou em conta as peculiaridades do mercado brasileiro e apresentou inovação tecnológica, mesmo com a utilização de equipamentos tradicionalmente utilizados em fecularias para a produção de amido de milho, bem como a alteração no processo de maceração. O novo processo foi implementado em uma unidade industrial da região Oeste do Paraná. Foram também realizadas análises físico-químicas dos grãos de milho, bem como do farelo de germe, do amido e dos farelos de glúten 60 e glúten 21, obtidos pela moagem úmida do milho degerminado, para comparar com os resultados encontrados na literatura, quando utilizado o processo de produção tradicional. Os resultados obtidos na caracterização realizada nas amostras utilizando o novo processo industrial foram similares aos encontrados na literatura utilizando o processo tradicional. Desta forma, os produtos podem ser comercializados normalmente.
\end{abstract}

Palavras-chave: milho, amido, farelos.

Abstract: The objective of this study was the development of a new process for the production of corn starch and byproducts for replacement of traditional processes. The new process considers the peculiarities of the Brazilian market and introduces technological innovation, with the use of equipment traditionally used in producing starch from corn, as well as the change in the process of maceration. The new process was implemented in an industrial unit in the western region of Paraná state. Physical and chemical analysis of corn, bran and germ, starch and gluten meal 60 and 21, obtained by wet milling of degerminated corn, were also conducted, in order to compare with results found in literature that employed the traditional production process. The results obtained in the characterization performed on samples using the new process were similar to those found in the literature using the traditional process. Thus, the products can be traded normally.

Keywords: corn, starch, gluten meal.

\section{INTRODUÇÃO}

O milho é uma fonte de energia, proteína, gordura e fibras tanto para o consumo humano como animal sendo, portanto, uma das principais matérias-primas para a indústria de alimentos. Entretanto, as mudanças que ocorrem durante o processo de maceração são responsáveis pela qualidade e rendimento dos produtos obtidos.

O processo que permite a obtenção de vários produtos derivados do milho inicia-se pela moagem úmida, que separa o grão nos seus componentes básicos: germe, fibra, amido e proteína (glúten). O principal objetivo da moagem úmida

\footnotetext{
1 Universidade Estadual de Maringá, Departamento de Engenharia Química, Av. Colombo, 5790, BL E46 - 09, CEP: 887020900 - Maringá - PR, Brasil. e-mail: claudigeraldi@onda.com.br, nehemias@deq.uem.br.

2 Universidade Tecnológica Federal do Paraná, Avenida Brasil, no 4232 - CEP 85.884-000 - CP 271 - Medianeira-PR. e-mail: laercio@utfpr.edu.br.

3 Universidade Estadual do Oeste do Paraná, Rua da Faculdade, 645 - Jd. Santa Maria- CEP 85903-000 - Toledo - Paraná. e-mail: tulio_klassen@onda.com.br.
} 
é a máxima recuperação possível do amido, com alta qualidade para uso industrial em geral (têxtil, papel e celulose, adesivos) e na indústria de alimentos, normalmente usado como amido modificado, para melhorar propriedades de vários produtos.

O principal e mais importante estágio da moagem úmida é a maceração dos grãos em solução de dióxido de enxofre sob condições controladas. As mudanças físicas, químicas e bioquímicas induzidas durante este período, são responsáveis pela qualidade e pelo rendimento dos produtos obtidos pós-moagem. $\mathrm{Na}$ indústria, os grãos são macerados com solução de $0,1-0,2 \%$ de $\mathrm{SO}_{2}$ e na temperatura de $50-54{ }^{\circ} \mathrm{C}$, por 48 horas. As condições do processo permitem o desenvolvimento de Lactobacillus sp., que, a partir da utilização dos açúcares solúveis na água de maceração, produzem ácido lático, reduzindo o $\mathrm{pH}$ do meio e promovendo condições favoráveis para a separação dos componentes do grão. Outros fenômenos que ocorrem nesta etapa são o amolecimento dos grãos, a liberação dos grânulos de amido das matrizes de proteínas por meio da quebra das pontes de enxofre e a inibição do crescimento de microorganismos de deterioração (ECKHOFF, 1991). Esta operação requer grandes investimentos, elevados custos de manutenção, grandes espaços físicos de instalações, longos períodos, assim como um alto consumo de energia (ECKHOFF, 1991), que limitam a taxa de produção de amido.

Neste trabalho, foi proposta uma alteração no processo de produção de amido de milho em relação ao tradicional. Desta forma, foi necessário desenvolver um fluxograma próprio que permitisse a identificação de parâmetros para a otimização operacional.

Portanto, estudou-se e desenvolveu-se um novo processo, que permitisse flexibilidade operacional e redução, tanto dos custos dos equipamentos quanto de processamento, e que viabilizasse a simulação, proporcionando condiçôes de avaliação e otimização operacional.

Para tanto, o processo apresentado na Figura 1, conta com uma inovação tecnológica, advinda dos processos tradicionais, caracterizada pela alteração no processo de maceração e na substituição dos tradicionais equipamentos utilizados na moagem de milho, pelos utilizados convencionalmente em fecularia (moagem de raíz de mandioca). Ressaltamos ainda que, neste processo proposto, a maceração é realizada com o milho já degerminado, ao invés do grão de milho inteiro como nos processos tradicionais.

A utilização destes equipamentos minimiza os custos de instalação das plantas industriais para moagem de milho, possibilitando assim instalações de pequenas plantas industriais para processamento de milho pelo processo via úmida.

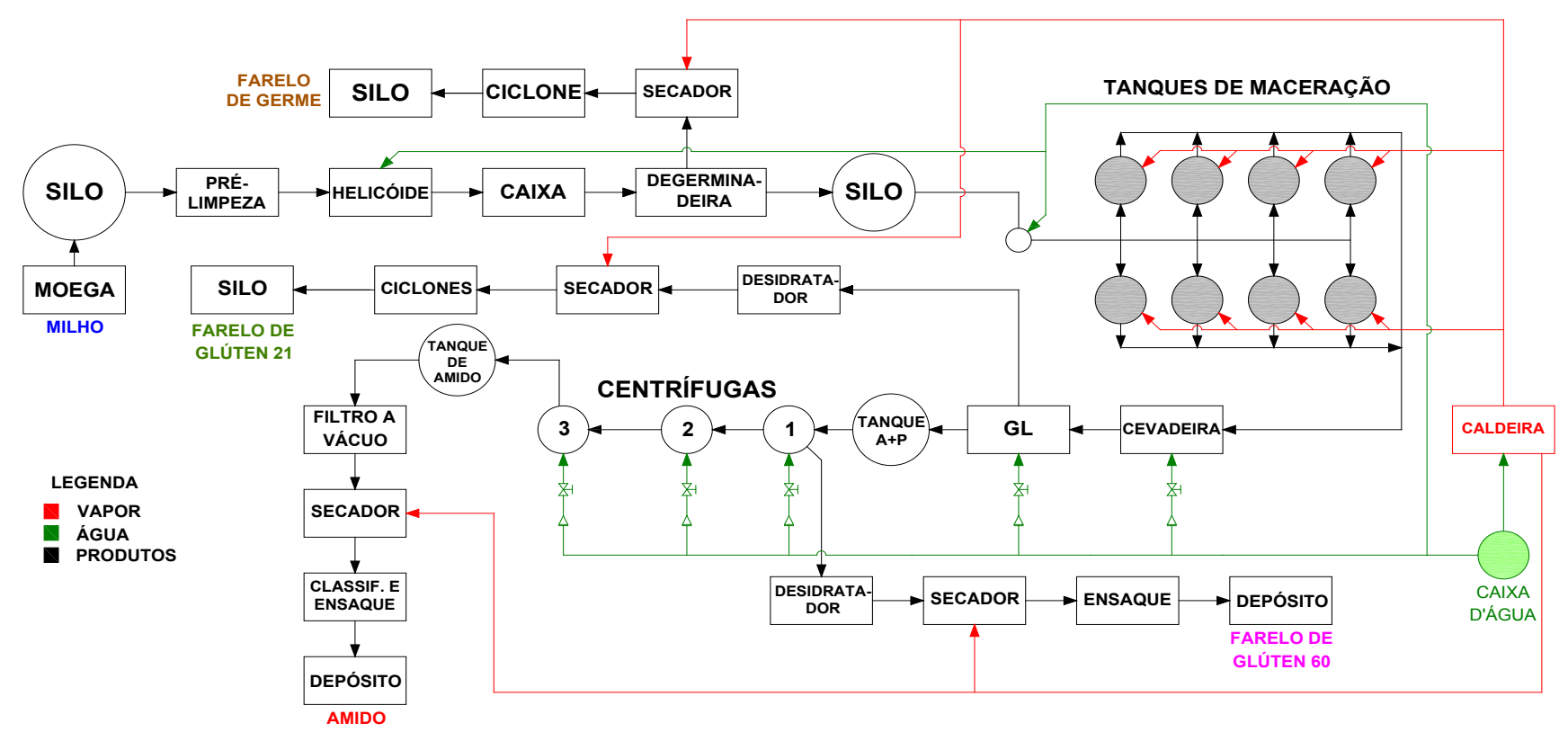

Figura 1. Fluxograma do processo proposto para a produção de amido de milho e dos farelos. 
Uma das grandes diferenças entre os processos de produção de amido é que, no processo tradicional, o milho é macerado inteiro e os tanques de maceração são conectados entre si por um sistema de tubos e bombas que movimentam a água de um tanque para o outro, passando através de trocadores de calor para aquecimento da solução. Neste tipo de operação, os grãos com maior tempo de maceração estão em contato com a água mais recentemente introduzida no sistema, que contém pequenas quantidades de sólidos solúveis e elevado teor de $\mathrm{SO}_{2}$. $\mathrm{O}$ milho mais novo do sistema recebe a solução que já passou por todos os outros tanques, contendo, portanto, grandes quantidades de sólidos e baixos teores de $\mathrm{SO}_{2}$. É a partir deste momento que, por cerca de oito horas, ocorre o desenvolvimento de fermentações láticas.

No processo de produção proposto neste trabalho, o grão de milho é degerminado e, depois, bombeado para os tanques de maceração, nos quais a solução de maceração permanece no mesmo tanque do início ao fim, sem a necessidade de troca entre os tanques, sendo a circulação da água promovida no próprio tanque. $\mathrm{O}$ aquecimento da solução de maceração é promovido pela adição direta de vapor no tanque de maceração.

O objetivo deste trabalho foi propor um novo processo e realizar uma análise econômico-financeira de uma planta para produção de amido de milho, permitindo assim um comparativo de custos de amido produzido (simulado neste trabalho) e o praticado pelo mercado. Além disso, foram verificadas as características físicas e químicas dos grãos de milho, do farelo de germe (obtido pelo processo de degerminação a seco), do amido, do farelo de glúten 60 e do farelo de glúten 21 pelo processo de moagem úmida. Para isto, foram utilizados grãos de milho produzidos na região Oeste do Paraná, da safra 2007/2008. Os rendimentos de farelo de germe foram determinados utilizando-se o processo de moagem seca, enquanto que o amido e os subprodutos foram obtidos a partir da moagem úmida utilizando o processo de maceração não convencional. Análises de proteína foram realizadas em todos os produtos obtidos nas moagens para verificar a pureza dos mesmos e a eficiência do processo.

\subsection{DESCRIÇÃO DAS ETAPAS DO PROCESSO}

\subsubsection{Transporte}

O milho é transportado até a planta industrial por meio de caminhôes graneleiros.

\subsubsection{Recepção e pesagem do milho}

O processo se inicia com a recepção e pesagem das cargas de milho. Após a identificação dos caminhões e da análise do produto, o milho segue para a moega em concreto, onde é descarregado. Os grãos de milho são então transportados por meio de elevadores de canecos para o silo de armazenagem.

\subsubsection{Silo de armazenagem}

Os grãos de milhos são estocados em silos de armazenagem com umidade máxima de 14\% (conforme contratos assinados com os fornecedores), para evitar o desenvolvimento de aflatoxinas.

\subsubsection{Pré-limpeza}

O milho recebido é limpo, para remover materiais estranhos como pedaços de sabugo, partículas metálicas e pó. Esta operação é feita com peneiras e eletroímãs.

\subsubsection{Degerminadeira}

A degerminadeira é utilizada para fracionar o grão de milho em canjica (milho sem germe e sem pericarpo) e farelo de germe. Neste equipamento, o milho entra previamente umedecido com água (umidade média de 18 a $20 \%$ ), e a caixa alimentadora da degerminadeira funciona como um silo pulmão. $\mathrm{O}$ farelo de germe proveniente da degerminadeira é seco em secador pneumático de corrente contínua tipo Flash Dryer, armazenado em silo e comercializado a granel como ingrediente para ração animal. A canjica resultante é macerada, para a produção de amido e do farelo de glúten 60 e 21 .

\subsubsection{Tanque de maceração}

Nos tanques de maceração ou maceradores, a canjica ficará por um período médio de 48 ho- 
ras, em água aquecida de 48 a $52{ }^{\circ} \mathrm{C}$, contendo pequenas quantidades de $\mathrm{SO}_{2}$ dissolvido, em torno de 0,1 a $0,2 \%$. O aquecimento da água de maceração é realizado através da injeção direta de vapor.

O ácido sulfuroso diluído, formado pela interação do dióxido de enxofre e da água, controla a fermentação, evitando excessivo crescimento bacteriológico, e ajuda na separação do amido. Durante a maceração, os componentes solúveis são extraídos do grão. Ao se concluir a fase de maceração, a água é drenada e armazenada em tanques, para ser utilizado no próximo tanque de canjica a ser macerada, a utilização desta água é continua, só é descartada parte da mesma quando esta atinge uma concentração em torno de 10 graus Baumé.

\subsubsection{Cevadeira}

O milho degerminado e macerado é bombeado através de bombas centrífugas para a cevadeira (uma espécie de moinho), onde é moído até se obter uma massa homogênea.

\subsubsection{Peneiras cônicas rotativas (GL)}

A massa homogênea proveniente $\mathrm{da}$ cevadeira é bombeada para um conjunto de peneiras cônicas (GL), onde é lavada com água (sob pressão), proporcionando a separação do amido e da proteína da massa resultante (bagaço). Após a lavagem, a suspensão de amido e proteína (farelo de glúten 60) é bombeada para uma centrífuga, e o bagaço resultante é comercializado como ingrediente para ração animal (farelo de glúten 21).

\subsubsection{Centrífuga}

Os componentes da suspensão formada pela água, amido e farelo de glúten 60 são separados por centrifugação. Como o amido difere em densidade, uma separação quase completa é obtida imediatamente. $\mathrm{O}$ amido ainda tem cerca de $2 \%$ de proteína, sendo então diluído e lavado até que seja removida quase totalmente a proteína, chegando a um amido com alta qualidade, tipicamente $99,7 \%$ de pureza, e uma concentração final de leite de amido de 18 a 20 Bé. A suspensão de farelo de glúten 60 é bombeada para um desidratador.

\subsubsection{Desidratador do farelo de glúten 60}

Por diferença de densidade, ocorre a separação do excesso de água da proteína (farelo de glúten), seguida da secagem em secador pneumático de corrente continua tipo Flash Dryer, sendo o farelo comercializado como ingrediente para ração animal.

\subsubsection{Desidratador de amido}

O amido concentrado nas centrífugas é bombeado do tanque de amido leite para um desidratador a vácuo, conhecido como filtro a vácuo, que, na prática, trata-se de uma tela cilíndrica perfurada, coberta por um tecido removível que em média deve ser substituido a cada oito horas. No desidratador, o amido concentrado é despejado, filtrado e desidratado a uma umidade média de $42 \%$, para, posteriormente, ser secado. Neste caso, também se pode usar um desidratador tipo piller que desidrata o amido a até $35 \%$ de umidade.

\subsubsection{Secagem}

O amido desidratado, proveniente do filtro a vácuo, segue por uma rosca sem fim a uma válvula rotativa que alimenta um secador pneumático de corrente continua tipo Flash Dryer. Neste equipamento, o produto é conduzido e seco por uma corrente de ar quente, previamente aquecida em um trocador de calor que utiliza vapor de água como fluido de aquecimento.

\subsection{O GRÃO DE MILHO: ESTRUTURA ANATÔMICA E COMPOSIÇÃO QUÍMICA}

Os grãos do milho são, geralmente, amarelos ou brancos, podendo apresentar matrizes, variando desde a cor preta até a vermelha. A massa individual do grão varia, em média, de 250 a 300 mg e sua composição média, em base seca, é $72 \%$ de amido, 9,5\% de proteínas, 9\% de fibra e 4\% de óleo. Conhecido, botanicamente, como uma cariopse, o grão de milho é formado por quatro principais estruturas físicas: endosperma, germe, pericarpo (casca) e ponta, conforme ilustra a Figura 2, as quais diferem em composição química e, também, na organização interna do grão. O endosperma representa cerca de $83 \%$ da massa do 
grão, o embrião, em média, $11 \%$ e o pericarpo, $5 \%$ (Mittelman, 2001). O endosperma é constituído por grânulos de amido envolvidos por uma matriz protéica.

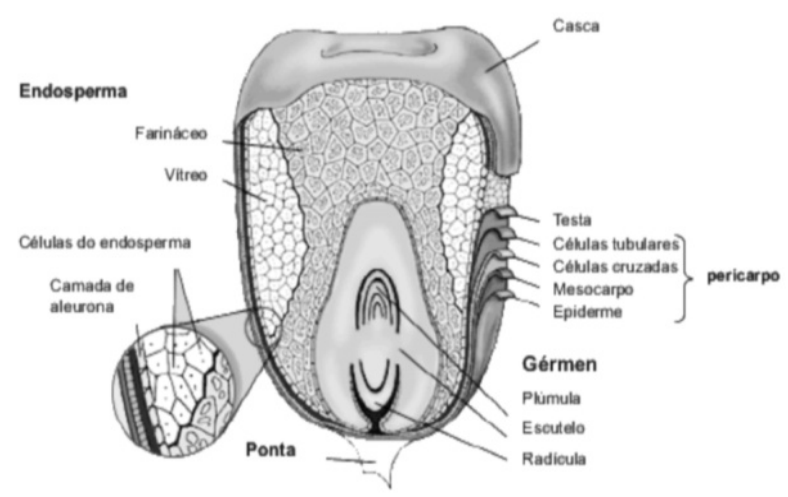

Figura 2. Anatomia do grão de milho e suas partes. Fonte: Adaptado de Britannica (2006), citado por Paes (2006).

A compactação é o fator mais importante da microestrutura relacionada à dureza dos grãos de milho, ou seja, quando os grãos são muito compactos tendem a ser duros, com altos valores de proteína e, no entanto, baixos valores de amido. A dureza de um grão possui dois significados: o primeiro é com relação à composição física do grão relacionada à textura do endosperma, que varia de vítrea até farinácea devido aos diferentes arranjos dos grânulos de amido e o segundo é com relação à força requerida para quebrar o grão (suscetibilidade à quebra) (Duarte, 2007).

\subsection{CARACTERÍSTICAS DO AMIDO DE MILHO}

O amido é o carboidrato de reserva da maioria dos vegetais superiores, ocorrendo como grânulos insolúveis em água, cujo tamanho e forma variam de acordo com a espécie e a maturidade da planta (Mittelman, 2001).

Os formatos dos grânulos de amido variam, sendo ovais, lenticulares ou esféricos, e apresentam diâmetros que variam desde 0,2 até $150 \mu \mathrm{m}$. $\mathrm{O}$ amido do milho contém dois tipos de moléculas: amilose e amilopectina, na proporção de $27 \%$ e $73 \%$, respectivamente, conferindo a esse ingrediente um alto valor energético, pois seu elevado conteúdo de amido encontra-se na forma facilmente digerível.

\subsection{FARELO DE GLÚTEN 60}

O farelo de glúten 60 é o resíduo seco de milho, obtido após a remoção da maior parte do amido, do germe e da separação do farelo pelo processo empregado na fabricação de amido de milho ou xarope, via úmida.

$\mathrm{O}$ ingrediente protéico de milho, protenose, é obtido por meio da separação e concentração do glúten extraído do milho pelo processo de moagem úmida. É denominado nas tabelas de nutrição animal como corn gluten meal (Santos, 2004).

\subsection{FARELO DE GLÚTEN 21}

O farelo de glúten 21 é um subproduto obtido a partir do processamento do milho por via úmida. É composto por fibras digestíveis do grão de milho e parte do glúten, além de parte do amido e frações protéicas não extraídas no processo primário de separação e enriquecidas com água de maceração concentrada. Nas tabelas de nutrição animal é também denominado como corn gluten feed (Santos, 2004).

\subsection{FARELO DE GERME DE MILHO}

O farelo de germe é composto do germe, tegumento e pequenas partículas amiláceas resultantes do processamento industrial do milho integral (Zea mays), empregado no preparo da farinha de milho para consumo humano ou animal. Deve ser isento de matérias estranhas à sua composição.

\subsection{DEFINIÇÕES SOBRE CUSTOS}

Antes que uma planta industrial possa ser colocada em operação, deve-se dispor de capital para comprar e instalar as máquinas e equipamentos necessários. Terreno e facilidades devem ser obtidos e a planta deve ser completamente estabelecida, com todas as tubulaçôes, controles e serviços associados. Além disso, é também necessário dispor de capital para o pagamento das despesas envolvidas na operação da planta durante o período inicial após sua partida (Peters E Timmerhaus, 1991).

De acordo com Perlingeiro (2005), o custo total é a soma dos custos diversos que compóem o empreendimento. 


\subsection{ESTIMATIVAS DE CUSTOS PARA PROJETOS DE PROCESSOS}

De acordo com Perlingeiro (2005), o desempenho previsto de um processo, ainda que se encontre em fase de projeto e o desempenho de um processo que já se encontre em fase de operação, pode ser medido por meio de critérios econômicos expressos por funçôes do tipo lucro ou custo. Muitas das estimativas de custos são feitas como parte da análise econômica de idéias propostas muito antes que o trabalho de projeto tenha sido feito. A precisão dos custos envolvidos durante a fase das estimativas pode ser maior ou menor de acordo com a quantidade e a qualidade das informações disponíveis para o projeto de um processo industrial. Turton et al. (2003) classificam as estimativas em ordem de magnitude, estudos, preliminares, definitivas e detalhadas.

A Figura 3 ilustra o custo para realizar estimativas em função da precisão esperada para a estimativa. Ou seja, quanto maior a quantidade de informações melhor será a precisão da estimativa e, consequentemente, maior o custo para realizá-la.

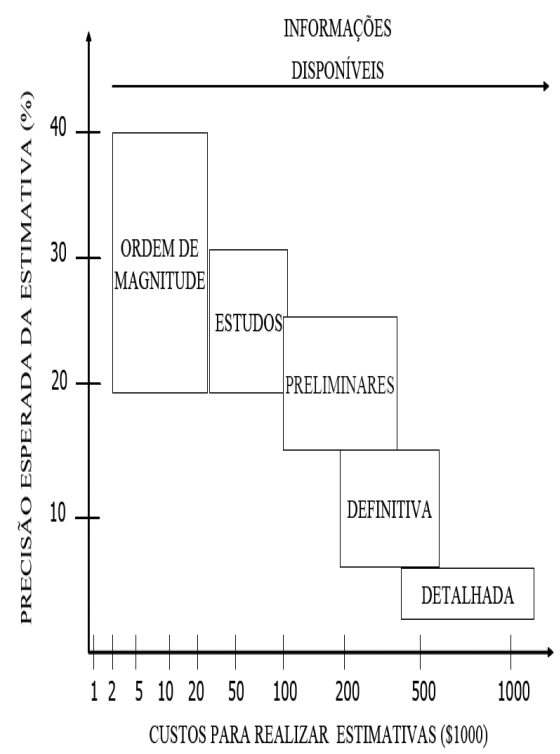

Figura 3. Precisão dos custos para realizar estimativas de acordo com a quantidade de informaçôes disponíveis para plantas industriais (adaptado de Turton et al., 2003).

Neste trabalho foi aplicada a estimativa detalhada dos custos de produção. Visto que o levantamento dos custos dos equipamentos foi realizada junto a fornecedores nacionais.

\subsection{ANÁLISE ECONÔMICA DE UM PROCESSO}

De acordo com Samanez (2002), o método do Custo Anual Equivalente (CAE) permite encontrar o custo anual (ou mensal) que equivale ao investimento inicial. Ou seja, mostra qual é a quantia uniforme que deve ser investida a cada ano (ou mês) durante a vida útil, de modo a igualar o investimento inicial. Para calcular o valor do CAE, é necessária a determinação do investimento no processo e a vida útil do projeto. A Equação 1 ilustra como efetuar o cálculo do valor do CAE.

$$
C A E=I_{\text {TOTAL }}+\sum_{t=1}^{N} \frac{F \cdot C_{t}}{\left(1+j^{*}\right)^{t}}
$$

$\mathrm{Na}$ Equação 1, as variáveis apresentadas têm o seguinte significado: $\mathrm{I}_{\text {TOTAL }}$ é o investimento total inicial para implementar o processo (US\$ ou R\$); CAE representa o custo anual equivalente (US\$ ou $\mathrm{R} \$$ ); t é a vida útil média dos equipamentos (ano) e $\mathrm{j}$ equivale aos juros anuais praticados no mercado financeiro, e F.Ct representa o fluxo de caixa no t-ésimo período (US\$ ou R\$). O tempo de vida útil de um projeto é uma decisão voluntária, baseada na identificação do possível resultado econômico-financeiro do negócio. Mesmo que se imagine uma vida útil infinita, para fins de estudo, é necessário fixar um horizonte temporal, não muito distante, que permitirá efetuar as análises desejadas e verificar se os empreendimentos são economicamente viáveis. Normalmente, este período pode coincidir com o tempo de vida útil dos principais equipamentos a serem utilizados. Samanez (2002) apresenta para máquinas e equipamentos uma taxa de depreciação e uma vida útil estimada de $10 \%$ e 10 anos, respectivamente.

\section{MATERIAIS E MÉTODOS}

O milho utilizado nas corridas experimentais neste trabalho foi do tipo híbrido simples, semiduro, levemente dentado, alaranjado, safra 2007/2008, produzido na região Oeste do Estado do Paraná, Brasil.

A planta industrial, que possui processo de extração de amido, farelo de glúten 60 , farelo de glúten 21 por via úmida, e farelo de germe por via seca, de onde originaram as amostras utilizadas 
nas corridas experimentais deste trabalho está localizada na região Oeste do Estado do Paraná. Foram realizadas as análises de teor de amido, teor de umidade, teor de proteína, extrato etéreo, teor de fibras e cinzas. Para a caracterização foram utilizados produtos provenientes do processo industrial.
As análises realizadas no milho, no farelo de germe, de glúten 60 , de glúten 21 e no amido estão apresentadas na Tabela 1 .

As análises foram realizadas conforme as metodologias apresentadas na Tabela 2.

Tabela 1. Conjunto das análises realizadas no grão de milho, amido e farelos.

\begin{tabular}{|l|c|c|c|c|c|}
\hline \multirow{2}{*}{ Análises } & Milho & $\begin{array}{c}\text { Farelo } \\
\text { germe }\end{array}$ & $\begin{array}{c}\text { Farelo } \\
\text { glúten 60 }\end{array}$ & $\begin{array}{c}\text { Farelo } \\
\text { glúten 21 }\end{array}$ & Amido \\
\cline { 2 - 6 } & $\mathrm{X}$ & $\mathrm{X}$ & $\mathrm{X}$ & $\mathrm{X}$ & $\mathrm{X}$ \\
\hline Umidade (estufa) & $\mathrm{X}$ & $\mathrm{X}$ & $\mathrm{X}$ & $\mathrm{X}$ & $\mathrm{X}$ \\
\hline Amido (ácido) & $\mathrm{X}$ & $\mathrm{X}$ & $\mathrm{X}$ & $\mathrm{X}$ & $\mathrm{X}$ \\
\hline Extrato etéreo (Soxleth) & $\mathrm{X}$ & $\mathrm{X}$ & $\mathrm{X}$ & $\mathrm{X}$ & $\mathrm{X}$ \\
\hline Proteína (Kjeldahl) & $\mathrm{X}$ & $\mathrm{X}$ & $\mathrm{X}$ & $\mathrm{X}$ & $\mathrm{X}$ \\
\hline Cinzas (mufla) & $\mathrm{X}$ & $\mathrm{X}$ & $\mathrm{X}$ & $\mathrm{X}$ & - \\
\hline Fibras & & & & & \\
\hline
\end{tabular}

Tabela 2. Metodologias utilizadas para a realização das análises no grão de milho, no amido e nos farelos.

\begin{tabular}{|l|c|}
\hline Análises & Metodologia de análise \\
\hline Umidade (estufa) & AOAC (1995) \\
\hline Amido (ácido) & $\begin{array}{r}\text { Rickard e Behn (1987) - teor de amido } \\
\text { Somogy-Nelson (Nelson, 1944 e Somogy, 1945) - dosagem de açúcares }\end{array}$ \\
\hline Extrato etéreo & AOAC (1995) \\
\hline Proteína & AOAC (1995) \\
\hline Cinzas (mufla) & AOAC (1995) \\
\hline Fibras & $\begin{array}{c}\text { Portaria no }{ }^{\circ} .108, \text { de 4 de setembro de 1991, do Ministério da Agricultura } \\
\text { Pecuária e Abastecimento do Brasil. }\end{array}$ \\
\hline
\end{tabular}

Para realizar a estimativa de custo, em reais por quilograma de amido de milho, foi utilizada a Equação 2.

Custo amido $=\frac{\mathrm{CAE}+\mathrm{C}_{\text {operacional por ano }}}{\text { Toneladas amido produzido anualmente }}$

$\mathrm{Na}$ Equação 2, a variável CAE é o custo anual equivalente e $\mathrm{C}_{\text {operacional por ano }} \mathrm{o}$ custo operacional por ano. $\mathrm{O}$ custo do amido refere-se ao amido pronto para ser comercializado. Este valor representa, de acordo com Samanez (2002), o custo anual uniforme equivalente para o processo que está sendo investigado.

\section{RESULTADOS E DISCUSSÃO}

\subsection{QUALIDADE DOS PRODUTOS DO NOVO PROCESSO}

Foram avaliadas as composições do grão de milho, amido, farelo de germe, farelo de glúten 60 e 21, visto que esta caracterização é de fundamental importância em projetos de engenharia envolvendo dimensionamento de equipamentos, armazenamento, secagem, etc., possibilitando assim uma simulação do processo global de produção de amido e subprodutos. Os resultados das 
análises realizadas nas amostras estão apresentados na Tabela 3.

Verifica-se pela Tabela 3, que os valores encontrados nas analises realizadas no grão de milho são similares aos resultados obtidos por Mussoline (2009) que obteve um teor de umidade variando de 11,86 a $12,2 \%$, um teor de proteína variando de 8,21 a 9,06\%, um teor de extrato etéreo de 3,0 a $4,77 \%$ e um teor de cinzas de 1,07 a $1,26 \%$, para quatro tipos de híbridos, para quatro tipos de híbridos, e GONÇALVES et al. (2003) que estudou dezesseis cultivares de milho, e obteve teores médios de proteína $9,76 \%$, cinzas $1,28 \%$, extrato etéreo de $4,41 \%$ e amido de $72,76 \%$, e por Paraman et al. (2010) que obteve um teor de óleo de $4,3 \%$ e um teor de proteína de $9,4 \%$ para o grão de milho.

Os resultados apresentados na Tabela 3, para o farelo de germe, são similares aos encontrados na literatura, exceto para as análises de extrato etéreo, visto que a maioria dos trabalhos refere se ao farelo de germe desengordurado.

Observa-se que o resultado obtido na Tabela 3, para o teor de proteína no farelo de glúten 60 é superior ao encontrado na literatura, isto porque neste trabalho o farelo de glúten 60 foi obtido pelo processo de moagem úmida do milho degerminado (canjica), enquanto que na maioria dos trabalhos o farelo é obtido da moagem úmida do milho integral. Resultados similares foram obtidos por Thompson et. al. (2006), Rausch et al, (2003a) e Rausch et al, (2003b) que obteve um teor de proteína de $62,6 \%$ para o glúten de milho (farelo de glúten 60).

Verificou-se também que o teor de proteína obtido no farelo de glúten 21 é inferior ao especificado pelo Ministério da Agricultura Pecuária e Abastecimento que é de $20 \%$, visto que, neste trabalho o farelo de glúten 21 foi obtido pelo processo de moagem úmida do milho degerminado (canjica), e não foi adicionada a água da maceração concentrada, o que eleva o teor protéico, como na maioria dos processos. Não foi adicionada devido o fato que para pequenas unidades industriais, não é economicamente viável em função dos custos dos evaporados para concentrar esta água.

Para as indústrias, níveis de 0,35 a $0,50 \%$ de proteína residual no amido são aceitáveis (Eckhoff et al., 1993). De acordo com Singh et al. (1997), embora a indústria de moagem úmida tenha por objetivo obter um amido com residual de $0,30 \%$ de proteína, valores de até $0,50 \%$ são aceitáveis para híbridos dentados. Assim sendo, o resultado médio do teor protéico no amido mostrado na Tabela 3, apresentou abaixo do especificado pela literatura, enquadrando facilmente nos padrões industriais.

Tabela 3. Resultados das análises realizadas em amostras de grãos de milho, farelo de germe, farelo de glúten 60 , farelo de glúten 21 e no amido expressos em percentagem em base úmida (média \pm desvio-padrão).

\begin{tabular}{|c|c|c|c|c|c|}
\hline & Grãos de milho & Farelo de Germe & Farelo de glúten 60 & Farelo de glúten 21 & Amido \\
\hline Umidade & $12.50 \pm 0.34$ & $11.08 \pm 0.53$ & $9.26 \pm 0.35$ & $11.04 \pm 0.53$ & $13.03 \pm 0.44$ \\
Amido & $71.86 \pm 0.62$ & $58.05 \pm 1.11$ & $12.57 \pm 1.07$ & $59.44 \pm 1.40$ & $86.52 \pm 0.44$ \\
Extrato Etéreo & $3.97 \pm 0.16$ & $12.35 \pm 0.48$ & $5.39 \pm 0.50$ & $4.24 \pm 0.64$ & $0.09 \pm 0.01$ \\
Proteína & $8.43 \pm 0.36$ & $11.82 \pm 0.62$ & $67.68 \pm 0.57$ & $15.60 \pm 0.45$ & $0.26 \pm 0.45$ \\
Cinzas & $1.21 \pm 0.05$ & $2.21 \pm 0.22$ & $2.75 \pm 0.41$ & $4.20 \pm 0.56$ & $0.10 \pm 0.02$ \\
Fibras & $2.04 \pm 0.12$ & $4.48 \pm 0.19$ & $2.35 \pm 0.37$ & $5.48 \pm 0.48$ & 0.00 \\
\hline
\end{tabular}


Tabela 4. Curvas obtidas para equipamentos nacionais em função do tipo e do intervalo de operação válido.

\begin{tabular}{|c|c|c|c|c|}
\hline Equipamentos & Curvas & & $\begin{array}{c}\text { Principais características do } \\
\text { equipamento }\end{array}$ & Intervalo Válido \\
\hline Bombas & $C_{\text {bomba }}=3702,98+263,58 \cdot b h p+2,269 \cdot$ bhp $^{2}$ & $(03)$ & $\begin{array}{l}\text { Construída em aço inóx (AISI } \\
\text { 304L). Resistentes a variações de } \\
\text { pH. }\end{array}$ & $5 \mathrm{cv} \leq \mathrm{bhp} \leq 20 \mathrm{cv}$ \\
\hline $\begin{array}{l}\text { Tanques aço } \\
\text { inoxidável }\end{array}$ & $\mathrm{C}_{\text {tinóx }}=7910,96 \cdot \mathrm{V}_{\mathrm{i}}^{0,6499}$ & (04) & $\begin{array}{l}\text { A relação entre o diâmetro (D) e } \\
\text { a Altura }(\mathrm{H}) \text { é dada por } \mathrm{H}=2,5 \\
\text { D. Construído em aço inóx (AISI } \\
\text { 304L). Possuem fundo inclinado. }\end{array}$ & $2 \mathrm{~m}^{3} \leq \mathrm{V}_{\mathrm{i}} \leq 20 \mathrm{~m}^{3}$ \\
\hline $\begin{array}{l}\text { Tanques } \\
\text { polipropileno }\end{array}$ & $\mathrm{C}_{\text {tprolip }}=4841,50 \cdot \mathrm{V}_{\mathrm{p}}^{0,852}$ & $(05)$ & $\begin{array}{l}\text { Construído em polipropileno. } \\
\text { Composto de uma parte cilíndrica } \\
\text { e uma parte cônica. Estes tanques } \\
\text { possuem uma estrutura metálica, } \\
\text { para dar sustentação. }\end{array}$ & $25 \mathrm{~m}^{3} \leq \mathrm{V}_{\mathrm{p}} \leq 100 \mathrm{~m}^{3}$ \\
\hline $\begin{array}{c}\text { Secador } \\
\text { pneumático }\end{array}$ & $\mathrm{C}_{\text {secador }}=11332,72 . \mathrm{Cs}^{0,8889}$ & $(06)$ & $\begin{array}{l}\text { Construído aço inóx (AISI 304l). } \\
\text { Possui exaustor. }\end{array}$ & $4 \mathrm{t} / \mathrm{dia} \leq \mathrm{Cs} \leq 80 \mathrm{t} / \mathrm{dia}$ \\
\hline Classificador & $C_{\text {class }}=-13075+2752,75 \cdot C c-6,562 \mathrm{Cc}^{2}$ & $(07)$ & $\begin{array}{l}\text { Construído em aço inóx (AISI } \\
\text { 304L). Possui ensacadeiras } \\
\text { acopladas, em aço inóx (AISI } \\
\text { 304L). }\end{array}$ & $20 \mathrm{t} / \mathrm{dia} \leq \mathrm{Cc} \leq 80 \mathrm{t} / \mathrm{dia}$ \\
\hline Degerminadeira & $\mathrm{C}_{\text {deger }}=34256,50 \cdot \mathrm{Cd}^{0,656}$ & (8) & Construída aço inóx (AISI 304L). & $2 \mathrm{t} / \mathrm{h} \leq \mathrm{Cd} \leq 5 \mathrm{t} / \mathrm{h}$ \\
\hline Ciclones & $C_{\text {ciclones }}=-1329,217+1811,16 \cdot \operatorname{Csp}^{0,8747}$ & (09) & Construído aço inóx (AISI 3041). & $4 \mathrm{t} / \mathrm{dia} \leq \mathrm{Csp} \leq 80 \mathrm{t} / \mathrm{dia}$ \\
\hline Silo fundo reto & $\begin{array}{l}\mathrm{C}_{\text {sreto }}=41440,089+28,951 . \mathrm{CAsr}^{1,2461} \\
(10)\end{array}$ & & $\begin{array}{l}\text { Construído em aço carbono } \\
\text { SAE } 1010 \text {. Possuem } 2 \text { portas de } \\
\text { inspeção. Não possuem sistema } \\
\text { de ventilação forçada, e nem } \\
\text { secadores acoplados. }\end{array}$ & $100 \mathrm{t} \leq \mathrm{CA} \leq 800 \mathrm{t}$ \\
\hline $\begin{array}{l}\text { Silo fundo } \\
\text { cônico }\end{array}$ & $C_{\text {scônico }}=-3517,009+3435,367$. CAsc $^{0,6122}$ & (11) & $\begin{array}{l}\text { Construído em aço carbono } \\
\text { SAE 1010. Possuem } 1 \text { porta de } \\
\text { inspeção. Possuem fundo cônico. }\end{array}$ & $1 \mathrm{t} \leq \mathrm{CA} \leq 100 \mathrm{t}$ \\
\hline
\end{tabular}

\subsection{ESTIMATIVA DE CUSTOS}

$\mathrm{Na}$ Figura 4, podem-se observar descontinuidades dos valores ao longo da curva. Essas mudanças de valores têm como justificativa as dimensões dos equipamentos que integram o processo de produção de amido, ou seja, ocorre uma mudança nos custos devido às faixas de operação fornecidas pelos fabricantes.

Foram levantados os custos dos equipamentos junto aos fornecedores nacionais em função da capacidade de operação, ajustadas curvas para esses custos para os principais equipamentos e realizadas uma simulação. As curvas de custos e o intervalo de operação estão apresentados na Tabela 4.De acordo com a Figura 4, para capacidade de moagem de 60 toneladas por dia, o custo médio do amido de milho, é de aproximadamente 0,83 reais por quilograma. 


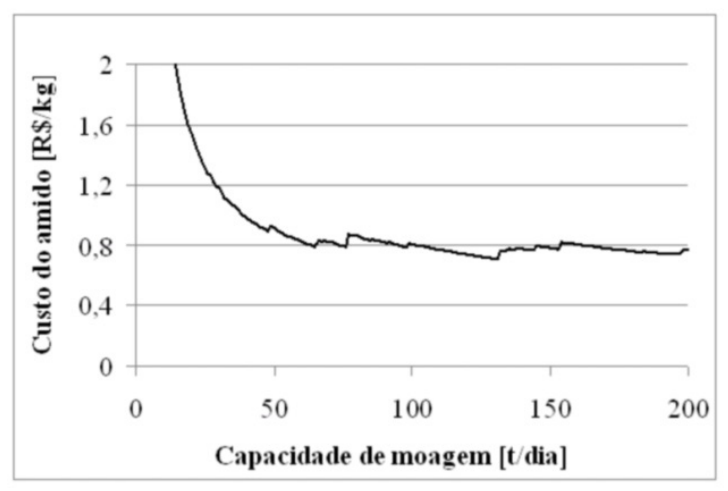

Figura 4. Custo do amido de milho em função da capacidade de moagem

A partir destes resultados, pode-se realizar uma estimativa para o custo do amido de milho quando comparado com o praticado pelo mercado e com a fécula de mandioca, a Figura 5 apresenta esta comparação.

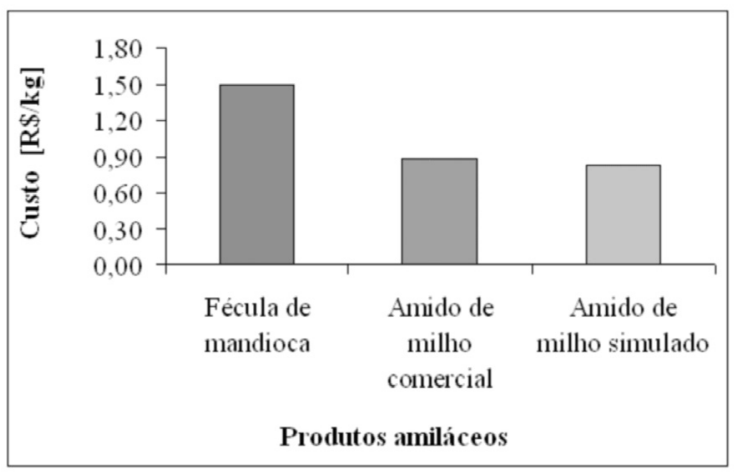

Figura 5. Comparativo de custo da fécula de mandioca, amido de milho comercial e do processo em estudo.

O método do custo anualizado equivalente mostrou-se adequado para a estimativa do custo do quilograma de amido de milho produzido. Para tanto, foram utilizados valores indicados por autores brasileiros como sendo os mais comuns nos projetos de novos processos. Ao comparar os valores do quilograma de amido produzido com o praticado pelo mercado, (AF NEWS, 2010) e com a fécula trabalho, apresentou valores extremamente competitivos.

Verifica-se que a adaptação de equipamentos de fecularia a moagem de milho é economicamente viável, o que possibilita a utilização da estrutura de uma fecularia na moagem de milho na entressafra de raiz de mandioca, evitando assim demissóes de funcionários e um maior lucro.

A Figura 6 ilustra os resultados obtidos na estimativa do fluxo de caixa em função do tempo.

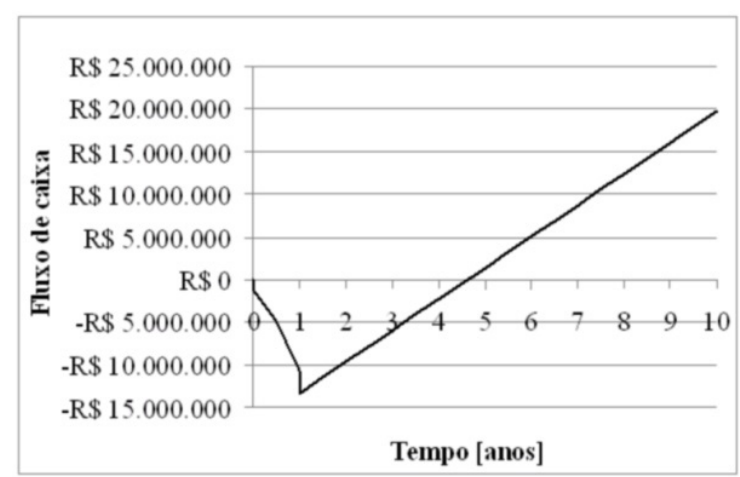

Figura 6. Fluxo de caixa para as estimativas de um projeto para produção amido de milho.

Através da Figura 6, pode-se observar que o tempo de vida útil do projeto é de dez anos, e para uma capacidade de moagem de 60 toneladas dia, o tempo total de recuperação do capital investido é de aproximadamente quatro anos e meio, o que torna o investimento economicamente viável.

A simulação foi realizada com base no amido de milho, visto ser o produto e maior quantidade no grão e o de interesse, os valores dos farelos (glúten 60, glúten 21 e germe) foram fixados conforme valor praticado pelo mercado.

$O$ custo do grão de milho utilizado na simulação foi de $\mathrm{R} \$ 301,00$ /tonelada, o do farelo de glúten 60 de $\mathrm{R} \$ 1.005,00$ /tonelada, o do farelo de glúten 21 de $\mathrm{R} \$ 250,00 /$ tonelada e o farelo de germe de $\mathrm{R} \$ 300,00$ /toneladas dados obtidos do CEPEA E AF NEWS em abril de 2010).

\section{CONCLUSŌES}

Pode-se observar que os resultados obtidos nos experimentos (caracterização), dos produtos pelo processo de moagem úmida são similares aos encontrados na literatura, mesmo utilizando processo de produção diferente, com estes resultados podemos verificar que os produtos se enquadram nos padróes industriais.

O método do Custo Anualizado Equivalente mostrou-se adequado para a estimativa do custo do quilograma de amido de milho produzido.

Observa-se que o custo do amido simulado neste trabalho é competitivo com o praticado pelo mercado, o que torna a implementação da planta viável para a condição simulada.

Observa-se que o amido de milho produzido com o novo processo é economicamente viável, o que possibilita as fecularias, principalmente as de pequeno e médio porte, utilizarem a estru- 
tura na entressafra da raiz de mandioca para a produção de amido de milho e seus subprodutos, fazendo apenas pequenas adaptação, possibilitando assim a unidade industrial produzir o ano todo.

\section{REFERÊNCIAS}

AF NEWS - Disponível em: <www.afnews.com. br>; Acesso em: 26 Abril 2010.

ASSOCIATION OF OFFICIAL ANALYTICAL CHEMISTS (AOAC). Official Methods of Analysis of the Association of Official Analytical Chemists. 16. ed. Arlington, $1995.2 \mathrm{v}$.

BRASIL, MINISTÉRIO DA AGRICULTURA, DA PECUÁRIA E DO ABASTECIMENTO. Portaria no 108 , de 04 de Setembro de 1991 e Portaria no 07, de 09 de Novembro de 1988.

DUARTE, A. P. A aparência engana. Revista Cultivar, p. 10-12, mar. de 2007.

ECKHOFF, S. R. AND TSO, C.C. Wet milling of corn using gaseous $\mathrm{SO}_{2}$ addition before steeping and the effect of lactic acid on steeping. Cer. Chem. v. 68 n. 3, p. 248-251, 1991.

ECKHOFF, S.R.; JAYASENA, W.V.; SPILLMAN, C.K. Wet milling of mize grits. Cer. Chem., Saint Paul, v. 70, n. 3, p. 257-9, 1993.

ENCYCLOPEDIA BRITANNICA, 2006. Disponível em: www.britannica.com.

GONÇALVES, R. A.; SANTOS, J. P.; TOMÉ, P. H. F.; PEREIRA, R.G.F.A.; ASCHER, J.

MITTELMAN, A. Variação genética para qualidade nutricional em milho com endosperma normal. 2001. 93 p. Tese (Doutorado) - Escola Superior de Agricultura Luiz de Queiroz, Piracicaba.

MUSSOLINI, R. C. Caracterização físico-química e rendimento da moagem úmida de quatro híbridos de milho. 2009. Dissertação (mestrado) - Universidade Estadual Paulista, Júlio de Mesquita Filho.

NELSON, N.A. Photometric adaptation of the Somogy method for the determination of glucose. J. Biolol Chem, v. 153, p.375-380, 1944.
PAES M.C.D.; Nutrição Humana e Ciência dos Alimentos, Embrapa Milho e Sorgo - Circular Técnica No. 75, 2006.

PARAMAN I., FOX, S. R., ASPELUND, M. T., GLATZ, C. E., JOHNSON, L. A, 2010. Recovering corn germ enriched in recombinant protein by wet-frationation. Biores Technol. 101, 239-244.

PERLINGEIRO, C.A.G. Engenharia de processos - análise, simulação, otimização e sintese de processos químicos. São Paulo: Edgard Blücher, 2005.

PESQUISAS APLICADAS EM AGRONEGÓCIOS, ECONOMIA SOCIAL E AMBIENTAL; www.cepea.org.br; acesso em 26/04/2010.

PETERS, M. S.; TIMMERHAUS, K. D. Plant design and economics for chemical engineers. 4. ed. New York: McGraw Hill, 1991.

RAUSCH, K. D., THOMPSON, C. I., BELYEA, R. L., CLEVENGER, T. E., TUMBLESON, M. E, 2003a. Characterization of gluten processing streams. Biores Technol. 89, 163-167.

RAUSCH, K. D., THOMPSON, C. I., BELYEA, R. L., TUMBLESON, M. E, 2003b. Characterization of light gluten and light steep water from a corn wet milling plant. Biores Technol. 90, 49-54.

RICKARD, J. E.; BEHN, K. R. J. Evoluation of acid and enzyme hydrolitic methods for determination of cassava starch. Journal of Scienc and Food Agricul., v.41, p.373-379, 1987.

SAMANEZ, C.P. Matemática financeira - aplicaçôes à análise de investimentos. 3. ed. São Paulo: Prentice Hall, 2002.

SANTOS, F. A. Revista Eletrônica Nutritime, V-1, no 3, p.79 - 100, Dezembro de 2004.

SINGH, V.; HAKEN, A. E.; DOWD, M. K.; NIU, Y. X.; ZOU, S. H.; ECKHOFF, S. R. Hybrid dependent effect of lactic acid on starches yields. Cer. Chem., Saint Paul, v. 74, p. 249 - 253, 1997.

TURTON R., BAILIE R.C., WHITING W.B., SHAEIWITZ J.A., Analysis, Synthesis, and Design of Chemical Processes, New Jersey: Prentice Hall, PTR, Upper Saddle River (2003). 